\title{
Matera (Basilicata, Southern Italy): A European Model of Reuse, Sustainability and Resilience
}

\author{
Marcello Bernardo ${ }^{*}$, Francesco De Pascale \\ Department of Languages and Educational Sciences, University of Calabria, Italy
}

Copyright (C) 2016 by authors, all rights reserved. Authors agree that this article remains permanently open access under the terms of the Creative Commons Attribution License 4.0 International License

\begin{abstract}
Europe is facing a severe crisis: old certainties are crumbling and traditional ways of working are showing signs of profound weakness. The first challenge, perhaps the most important, is to manage an advanced economy to generate not only economic value, but also social justice and environmental quality. The second major issue is to promote the adoption by civil society and institutions of an "ethos" within which citizens could plan, produce and co-create their cities, cultivating a new and more rich democratic awareness. Thirdly, it is about creating a climate of openness that enhances creative problem solving and provide a platform to think, plan and act together, with courage. Matera has what it takes to meet these challenges. Matera's story is told from its streets, its buildings, its monuments. They tell a story of ingenuity and resilience, disgrace and redemption, tinged by a deep sense of shame. The characters in this story are "Sassi”, which for over thirty years were left to decay, was a synonym of "national shame" and was the emblem of a southern backwater, in conflict with modernity. The awareness of its inhabitants of their age-old tradition, based on the ability to inhabit inhospitable places, to create a harmonious relationship with territory, has prompted many young people to return to inhabit the "Sassi" and to make them become "World Heritage Site" in 1993. Twenty years later, grandchildren of those brave young people have proposed to community a new victorious challenge: help to make Matera 2019 European Capital of Culture.
\end{abstract}

Keywords Matera, Resilience, Reuse, Sassi, Sustainability

«I arrived to Matera at about eleven in the morning. I had read in my guide book that it is a picturesque town worth visiting; there is a museum of ancient art and some curious cave dwellings [that is: carved into the rock]. As I started walking away from the train station, I came to a road that had one side lined with old houses, while the other ran along a precipice. Matera lies in that deep furrow. The shape of that ravine was peculiar; it looked like two half funnels positioned side by side, separated by a small outcrop and united at their base by a common peak, where you could see, from above, a white church. It was Santa Maria de Idris, and it looked like as if it was stuck into the ground. These inverted cones, these funnels, are locally known as "Sassi” [litt: “stones”]. Their shape reminded me of what, while at school, we imagined Dante's Inferno might have looked like. The narrow space between the facades and the slope accommodated roads, which serve as basements for those who come out from the top floor houses, and as roofs for those below. Looking up, I could finally see the whole of Matera as a slanting wall. It is really a beautiful city, picturesque and impressive».

Carlo Levi, Christ Stopped at Eboli [1]

\section{Introduction}

The writer Carlo Levi (1902-1975), in the novel that made him famous, Christ Stopped at Eboli (1945) (1), describes Matera as a city that is no longer able to sustain that ecosystem that had worked during the preceding centuries; he pleaded for the recovery and the revival of this city already since the 1940s. Levi's words refer to his own visit to the city, when the Sassi were at the peak of misery and social decline. The collapse, however, did not occur suddenly. It started between the second half of the eighteenth century and the early nineteenth century, with the decline and the disappearance of sheep and goat husbandry and of the protection of transhumance. This coincided with the industrial revolution and with the colonization of entire continents, through which the implementation of a new division of labor on a global scale came about. Australia came to dominate the market as the largest wool manufacturer and became the main supplier of the English textile industry, which absorbed much of the international wool production. The fall in wool exports towards England destroyed the economic relevance of the agro-pastoral system; throughout the country, regulations and institutions designed to protect grazing rights and transhumance came to an end. At Matera, during the eighteenth and nineteenth centuries, the modern city expands along the flat terrain that bordered the edge of the ravine by developing imposing administrative and religious 
buildings right where the ancient city used to have its businesses and its grains and water storage systems. The pits, barns, tanks, common wells, and the gardens located on the flats, which constituted crucial centres of the Sassi infrastructural system, became buried and hidden from the streets and palaces belonging to the new physiognomy of power [2]. This period, witnessed by Raffaele Giura Longo $[3,4,5]$ set the basis for a radical divide between the upper and the lower part of town. A marked difference stems out between the "peasant conditions", which became discriminated against by rest of the city. The ending of customary community agreements of space management, hygiene maintenance, and waste recycling, determined degraded and unhealthy conditions. The balance between available resources and the living space, which had given shape and size to houses and to the city it, became compromised. A process began, that progressively created the contemporary expansions of the urban area above the watershed lines, on top of the clays and of the springs that in the past had always been spared. The Sassi that had constituted the city became a refuge neighborhood, subordinated, inadequate, and saturated. This process reached its peak in 1952, when the then prime minister, Alcide De Gasperi, enacted a special law to order the evacuation of the Sassi. The inhabitants of Matera were forced to abandon their homes and to relocate to new homes in new neighborhoods; this event underlined a condition of long-term hardship and deeply frustrating social disorder.

The discovery made by Carlo Levi on behalf of an entire generation of Italian intellectuals was interpreted as a shock, a kind of trauma. The story of his first visit to the Sassi was entrusted to the sister of the writer, that is: to a second narrator, therefore to someone who might have written in a far more objective manner. Matera appears as the discovery of an original sin, the more serious the less we had realised its existence:

«... Inside those black holes through the earthen walls I could see the beds, the poor furnishings, rags lying about. Dogs, sheeps, goats and pigs were lying on the floor. Each family usually possessed just one of the caves and they would all sleep together, men, women, children and animals ... There was an infinity of children ... naked or in rags ... I saw children sitting in the doorway of their homes, in the dirt, under the scotching sun, their eyes half-closed and their eyelids red and swollen. It was trachoma. I knew that there was this kind of disease down here, but I was touched by seeing it among the filth and the misery, it was a different thing ... And the flies would rest on their eyes but they seemed not to mind ... their young faces wrinkled like old men and with a skeletal appearance due to the hunger: the hair full of lice and scabs ... Thin women with malnourished dirty infants attached to their withered breasts ... it felt like being in the middle of a city hit by plague ... » [1].

In addition to Levi's work of, numerous artists described the strong sense of decay and decline in the quality of life of the inhabitants of Matera in literature and in cinema. One of these is the portray made by Pier Paolo Pasolini (1922-1975) of the Sassi of Matera and the Murgia Nature Park, in his film The Gospel according to Matthew. It was realised entirely in Matera in 1964, in order to contribute to the development and to the revitalization not only of Matera, but of all of the Basilicata Region (Figure 1) at international scale. 


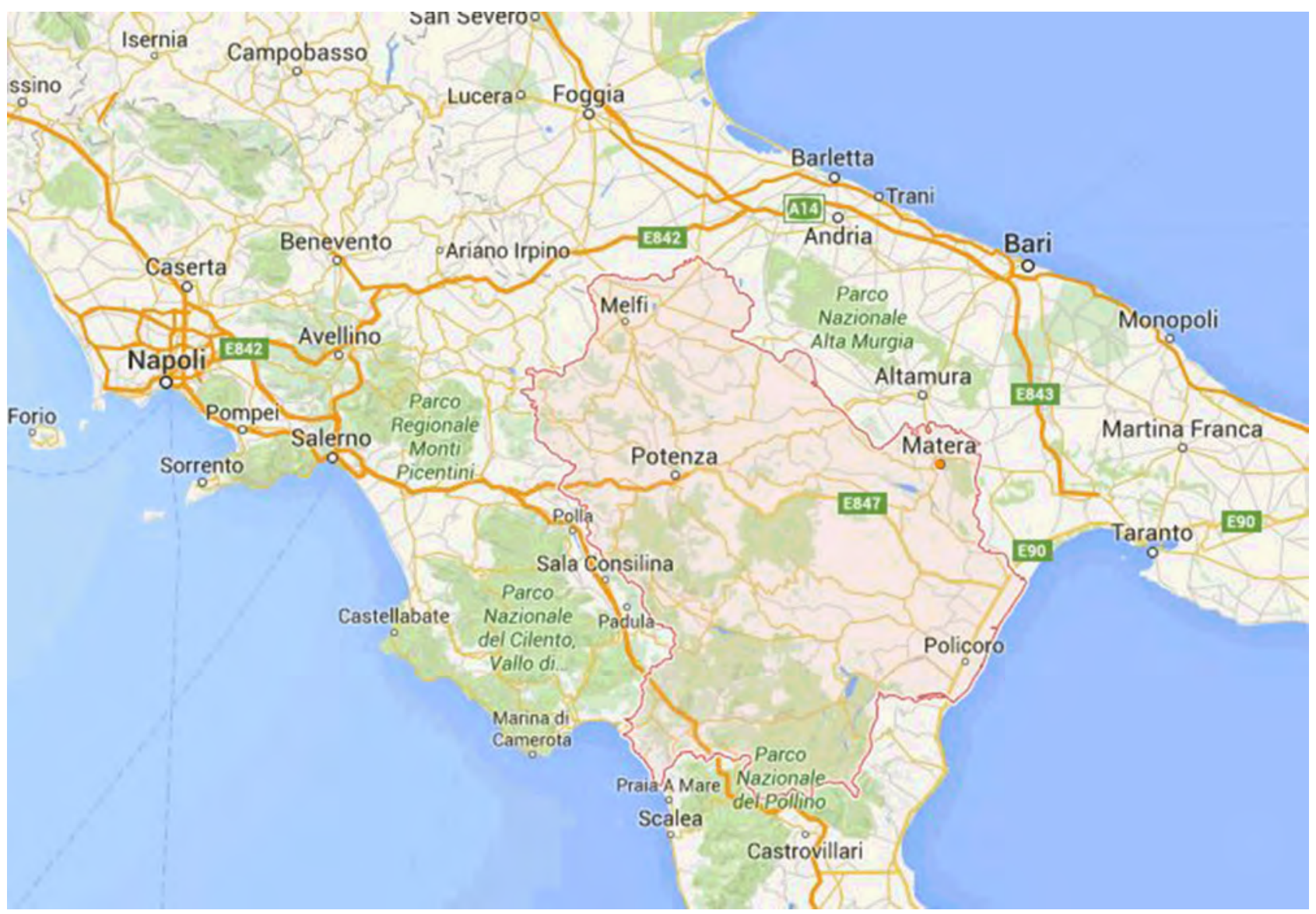

Figure 1. Basilicata (southern Italy). The geographic position of Matera Source: Google Maps

All these witnesses, despite being different from each other, were united under a same goal: to bring back dignity to the Sassi, to re-establish their glory and their historical and cultural importance, revamping Matera's prestige vaunted in medieval and modern times when descriptions full of admiration and appreciation for the beauty of the city abounded. In the twelfth century, Matera is described as being magnificent and full of splendour by the Muslim geographer El Idrisi who compiled for the Norman King Roger of Sicily, his famous description of the Earth. The sight of the Sassi inspired poets and writers. At night, hundreds of lanterns are lit in the caves; the degrading rambles of the Gravina are compared to the reversed vault of the starry sky. Down on earth Matera reflects the constellations high above. What is on earth conforms to what is in the sky: the sacred caves of the Sassi are the image of cosmic harmony [6]. In the utopia New World [7, 8], written at the beginning of the seventeenth century by Tommaso Stigliani, Matera is the symbol of the ideal city and a reminiscence of the Indian capital Peasantry.

This work focuses on three characteristics that recur often in the history of this city: reuse, sustainability and resilience. It pays particular attention to the latter concept, reconciling small pieces of the history of Matera told by its streets, its buildings, its monuments, from antiquity to the present day. The concept of resilience was borrowed from the field of materials science, where it is used to referring to inanimate objects (e.g. metals) that can withstand shock and dynamic loads even out of the ordinary, without losing their integrity [9]. Similarly, the concept of resilience was introduced in psychological sciences during the seventies $[10,11,12]$ to indicate the ability of individuals to show appropriate levels of competence after exposure to adversity and to significant difficulties [13, 14]. Applying these concepts to the realm of geography we shall use them with regard to natural disasters, but more generally to changes taking place in the landscape, referring to its ability to resist and to recover from losses. This concept is well suited to be used in the context of geographical analysis while assessing holistic human-environment relationships. It is able to incorporate within itself both a physical environmental dimension (as in physical geography), which covers the spatial dimension of the area affected by a given event, and a social dimension referring to socio-economic aspects of the social capital and of territorial governance [9].

The history of Matera is veined by degradation and shame, but also by redemption, resourcefulness and resilience. Immediately after the evacuation, particularly in the fifties and during the whole sixties of the twentieth century, the Sassi, from national disgrace, slowly and up to this day turned into an important site of experimentation and innovation. The process of re-evaluation of their locus began around the end of the eighties and culminated in 1993 through the UNESCO recognition of the Sassi as a World 
Heritage Site.

Matera made great efforts: from national disgrace it became the first city of the Italian South to be nominated as a world heritage; from an entirely unknown and "invisible" city, it became one of the major art cities to visit. It implemented major restoration works, but it has not yet reached its huge cultural potential. Its residents, twenty years after the UNESCO recognition, propose a new challenge: to nominate Matera "European Capital of Culture” in 2019. To run for the 2019 nomination implies delivering the city to a new strong impulse of ideals leading to a new transformation phase. It means becoming able to imagine a city passing from a development phase in which opportunities for a re-evaluation of its historical territory has been already taken -with its architectural and cultural content and with large impact upon tourism- to a new phase in which one of the aims is to attract permanent economic, cultural and technological talents and the other is to strengthen the sustainability of the overall project.

Matera, took this challenge, on the $17^{\text {th }}$ of October 2014, when it was designated, together with Plovdiv, as European Capital of Culture 2019. This was the first time for a city of the Italian South to receive this title. The city finally realized the concrete chance of becoming one of the most attractive cities not only of tourists, but also for valuable mobile resources (talents, creative industries), and of specializing in development sectors characterized by high added value.

The purpose of the present contribution is to try and highlight the virtues due to which Matera was listed as a UNESCO World Heritage Site, and then designated as European Capital of Culture in 2019. The City of the Sassi developed a new culture of urban planning and of cultural investment based on the key principles of infrastructure reuse rather than on new constructions, and on the principles of environmental sustainability and resilience.

A careful literature analysis was carried out bearing in mind the following two objectives:

a) to rebuild the historical-cultural and geo-economic processes that took place within the city of Matera;

b) to provide an update of recent developments, both theoretical and applied, of the on-going research about new urban planning and on the adoption of preventive policies concerning uncertainty management linked to the themes set out above.

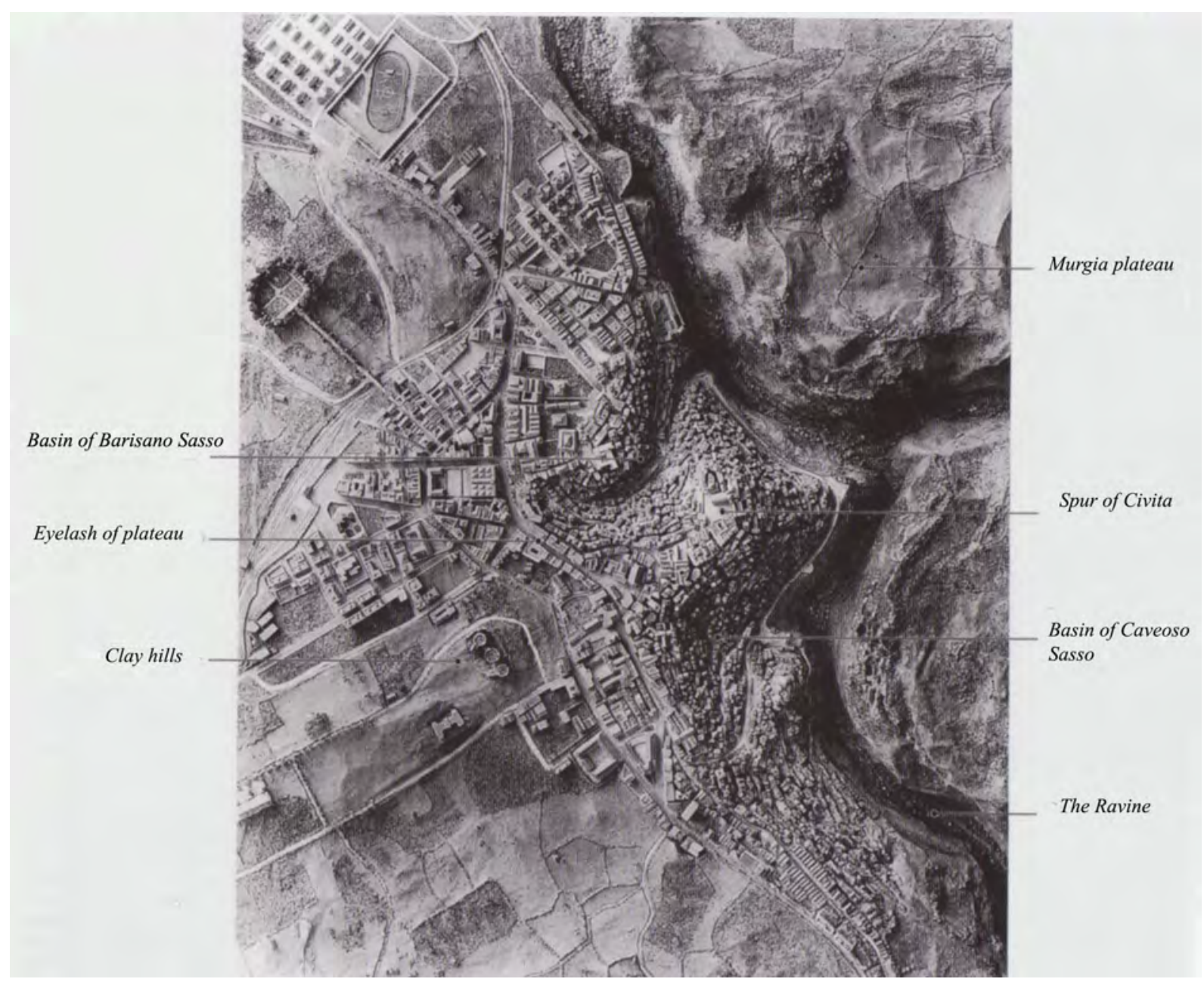

Figure 2. Natural and urban morphology of the Sassi. Source: plastic made in 1949 by F. Viti. 


\section{The History of Matera Stirred by Social, Economic and Environmental Drivers}

The history of Matera is mainly determined by the Sassi, i.e. outcrops, stones, rocks (Figure 2).

It is a housing system created in the bedrock itself; carved in a limestone rock called 'tuff' and used to build dry stone walls, terraces, streets and stairways. The Sassi are located along the slopes of a deep valley: the Gravina (=the Ravine).

In geographical terms, a ravine is shaped as a canyon with steep walls distant between each other, dug in the limestone collecting abundant water only during rainy periods, drained by temporary streams that during the dry season are almost nonexistent [2] (Figure 3).

The site of Matera has its roots in distant historical periods. The presence of man is documented since the Palaeolithic. That period saw the first settlements in the area of Matera, more precisely in the area that now corresponds to the Murgia Nature Park. Research carried out by Pietro Laureano on the Sassi ecosystem reveals that, initially local inhabitants settled into a series of caves, such as the Bat Cave, about $4 \mathrm{~km}$ from Matera, the largest of the several karst caves that open up along the steep slopes of the ravine, and the one below, called the Funeral Cave (Figure 4).

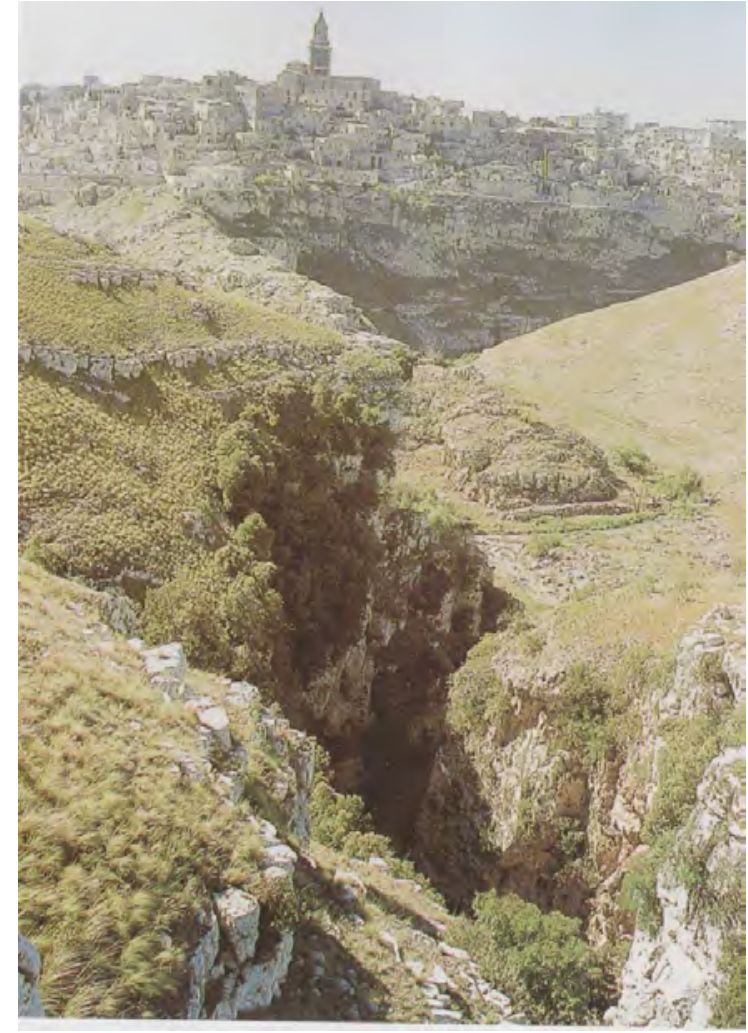

Figure 3. The steep crevasses of Iesce pouring in Ravine of Matera. Source: Laureano, 1993 [2]

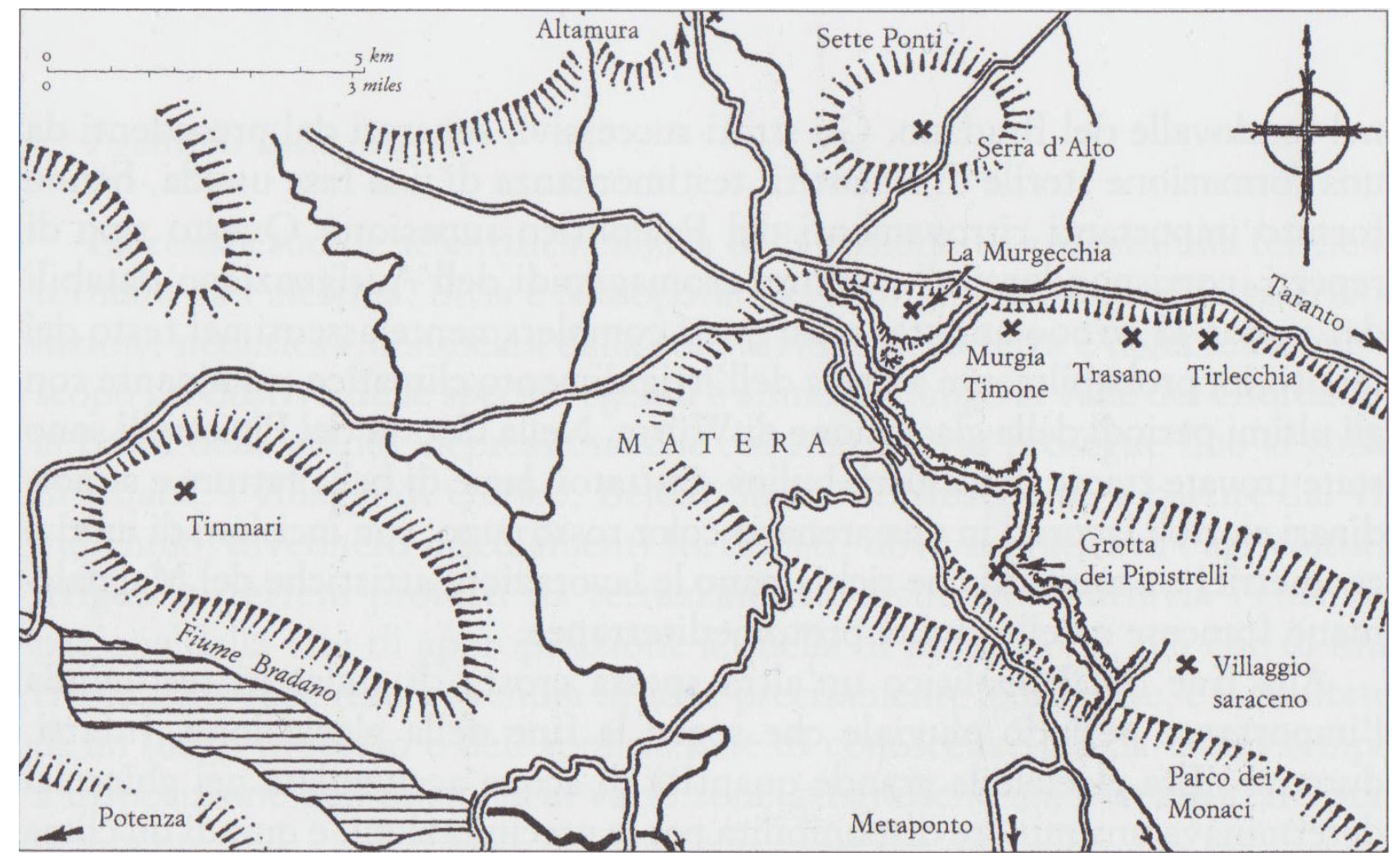

Figure 4. The main prehistoric sites of Matera. Source: Laureano, 1993 [2] 
These are the most ancient sites of Matera. The Bat cave is the last of a system, which was connected to a network of narrow corridors that could be followed only by bending and proceeding on all four, that communicated with small cavities belonging to other cave systems, some of which were hidden, others collapsed. The cave, which bears this unusual name because of several species of bats that live there, is of extraordinary importance due to the quantity and variety of findings, demonstrating human presence from the Paleolithic to the Neolithic, to the metal Age, and up to historical times. It is believed to represent one of the most ancient cities in the world, second only to Alep. Remains of fireplaces, large amounts of pottery and Neolithic tools were found in the Bats Cave. Its mysterious fascination over time stirred popular imagination, giving rise to myths and legends. The historian Domenico Ridola (1841-1932) was the first one who saw its true archaeological potential. Between 1872 and 1878, he led a series of excavations at the site that disclosed many artefacts belonging to various ages: from the Paleolithic to the Metals Age. Sites such as the Bat Cave were used since the Paleolithic, and had a ritual use rather than a residential one. It used to serve as sacred burial, shrine and temple. The same functions remain during the Neolithic, when the population lived in villages made of huts.

\subsection{The Neolithic Village of Murgia Timone}

Following the Paleolithic era, the whole area is targeted for the first time by numerous human settlements (Figure $5)$.

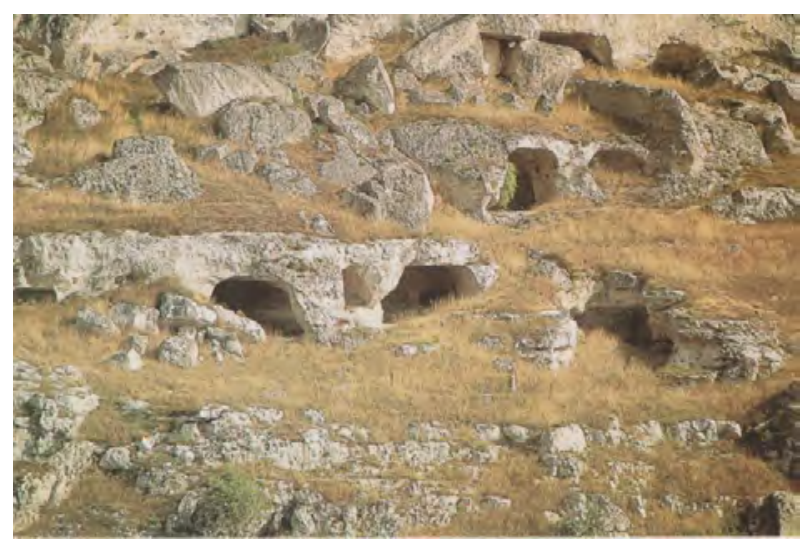

Figure 5. Gorges and caves are born in the limestone of the Murge, characterized by strong soil erosion and karst phenomena. Source: Laureano, 1993 [2]

True villages were built including defensive walls, huts, baking ovens, water tanks and burial mounds; the double circle tomb found in the Neolithic village of Murgia Timone being one example (Figure 6).

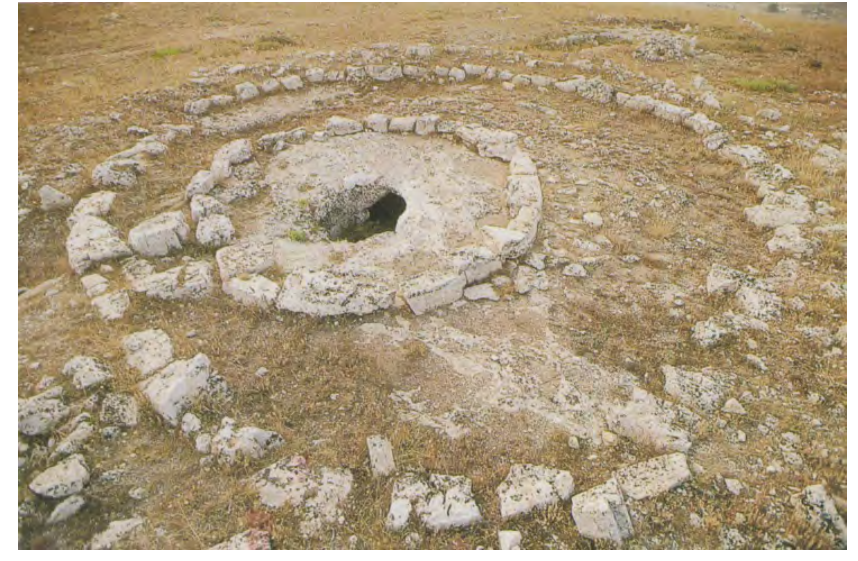

Figure 6. Monument of the Bronze Age of Murgia Timone, the calcareous plateau facing the city of Matera. Source: Laureano, 1993 [2]

In this area the early inhabitants found an ideal habitat for conducting the two activities on which they would base their livelihood: raising sheep and agriculture. Ideal local conditions improve the quality of life of these ancient inhabitants both from an economic point of view and from a social one. They decide to remain permanently here and to abandon nomadic life that had characterized their originary mode of living. Pietro Laureano adds:

«Among all Neolithic settlements, the region of Matera is one of the most important and the first to be studied in Italy. Up to our times, Matera is cited by worldwide scholars as one of the capitals of the European Neolithic Age and as the place that gave its name to well-defined styles of pottery. The limestone highlands, at the high edge above the Gravina of Matera, host the renown sites of Serra d'Alto, Murgia Timone, Murgecchia and Tirlecchia, where numerous permanent villages were found, whose chronology was not dissimilar from the one of the first sites from which agricultural techniques and neolithisation were disseminated» [2].

The commonest structures that date back to the Neolithic period are water tanks, whose bell shaped structure persisted over time in Matera, through the Metals Age until the historic time that gave origin to the Sassi. These structures testify the habit of collecting water to irrigate the gardens. In these drylands, knowledge of water collection and distribution is crucial for life. We are facing a system of tanks, micro-cisterns, simple cavities carved out of limestone outcrops serving as watering troughs, which also retain rainwater and make it available to passing-by herds, and the nervier, special caves for the collection of winter snow used for preserving food, and for a more appropriate control of water supply (Figure 7). 


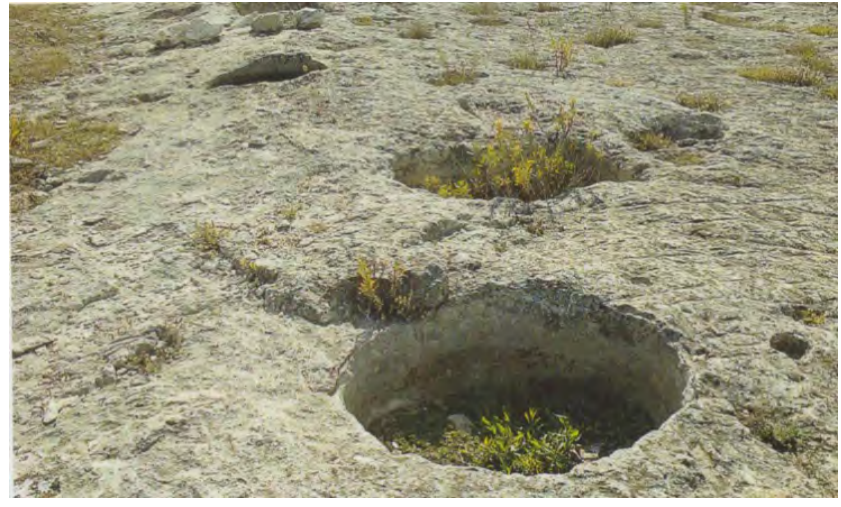

Figure 7. In the Neolithic village of Murgia Timone, the small part that was discovered, allowed the finding of cisterns for collecting water, carved in limestone. Source: Laureano, 1993 [2]

\subsection{The Settlement of Matera: A New Neolithic Economy}

The original studies conducted by Domenico Ridola, evidenced that in the Neolithic village of Murgia Timone, there is a system of tanks to collect rainwater and get drinking water through subsequent settling tanks dug into the limestone. It is a technique used since prehistoric times (Figure 8).

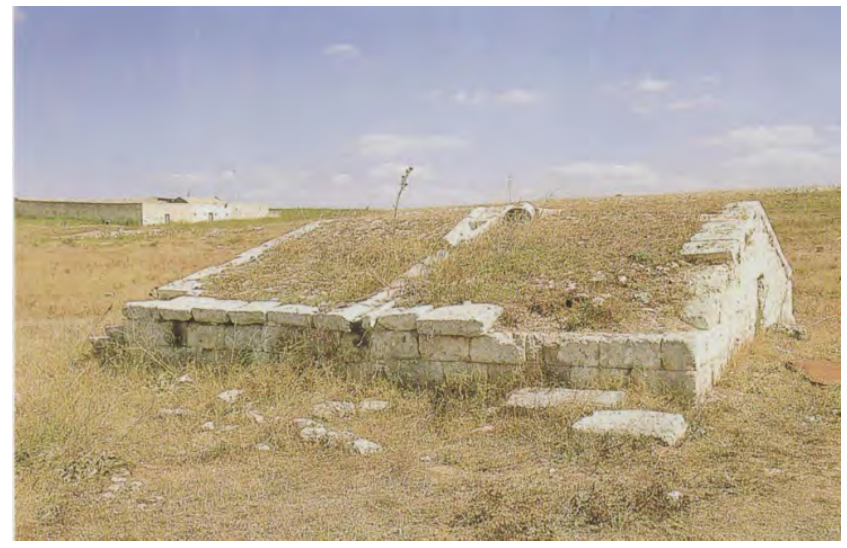

Figure 8. Roof tank, water production device on the Murge. Source: Laureano, 1993 [2]

These villages dispose of a moat resulting from the hard work of digging into the limestone. Impressed by these ancient trenches, Ridola defined the large prehistoric settlements of Matera "entrenched villages", very complex structures created in the shape of a labyrinth [15].

By the current state of knowledge, these ditches marking the perimeter of the villages keep an enigmatic meaning. It is not impossible that such perimeters should be interpreted in relation to the sacredness of the place. The way of life and the Neolithic economy provide an explanation for the origin of these labyrinths in the Matera villages. The etymology of labris ("stone" in Greek) is connected to the idea of an excavation, a typical aspect of Neolithic villages. The ritual function of labyrinthine paths continues to characterize the Bronze Age, where typical spiral shapes recall the movement of the stars from which energy-bringing fertility and success can be absorbed. But the moat is not just a symbolic architectural shape. It is also a utilitarian facility with the function of draining the soil and collecting water. It was also useful for the collection of manure that could be supplied to fields to maintain their fertility. This structure seems to have been functional to animal husbandry, as evidenced by the Caspian Sea graffiti and paintings and by the ones of the Saharan Neolithic (Figure 9).

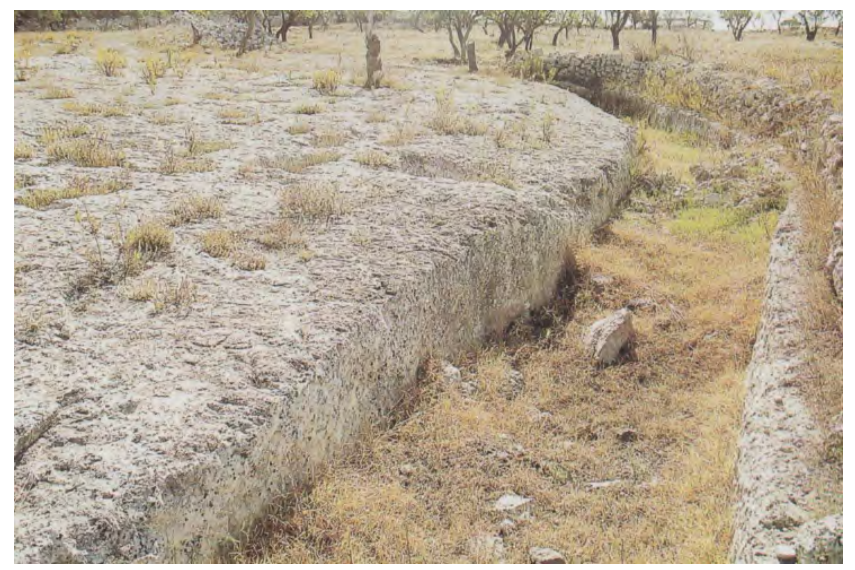

Figure 9. The big ditch, partially revealed, branded with a double ellipse the perimeter of the Neolithic settlement. Source: Laureano, 1993 [2]

\section{Transformation of a Water Tank into a Dwelling: Reuse}

During the Metals Age, a vast process began of excavating the edge of the ravine formed at an altitude comprised between 350 and 400 meters of a thick layer of soft limestones. The tuff is even more consistent along the eastern shore where two slits or blades called "grabiglioni" (small ravines) create two large riverbeds joined together by a higher tongue of limestone. The two natural grabiglioni amphitheaters have been the subject of intensive excavation and terracing for agro-pastoral use. Fragmentation and collection of water flow through the network of channels, water tanks and caves kept the ground protecting the slopes from destructive erosion. The plateau and the slopes above the edge of the Gravina were made up of clay-rich sources. At times of rain, water flows on the clay surfaces creating temporary lakes and wetlands. During dry periods, clays dry up and crack; springs dry up. The plateau and the clay-rich slopes with the fertile red land and the bolus formed by the degradation of the limestones are kept covered by woods and fields, free of buildings. Houses were built lower, along the meandering grabiglioni, gradually occupying the network of terraces, gardens and underground agropastoral spaces [6].

This is how the Sassi and their name, meaning stony ward, came about, making its first appearance in an early thirteenth century document that remained anonymous.

One of the Materan Sassi is called Caveoso. There can be no certainty about the interpretation of this name but it is 
quite likely that it derives from the Latin caveosus ("with many caves"), or due to its orientation towards the South, in the direction of Montescaglioso, that used to be called in Latin Mons Caveousus. The Caveoso, although was already inhabited in ancient times, started becoming an integral part of the city only in 1500 , the century that experienced a wave of immigration from the Balkans. Inside this Sasso, the homes are built one above the other, with a shape reminiscent of the steps of a classical amphitheater (Figure $10)$.

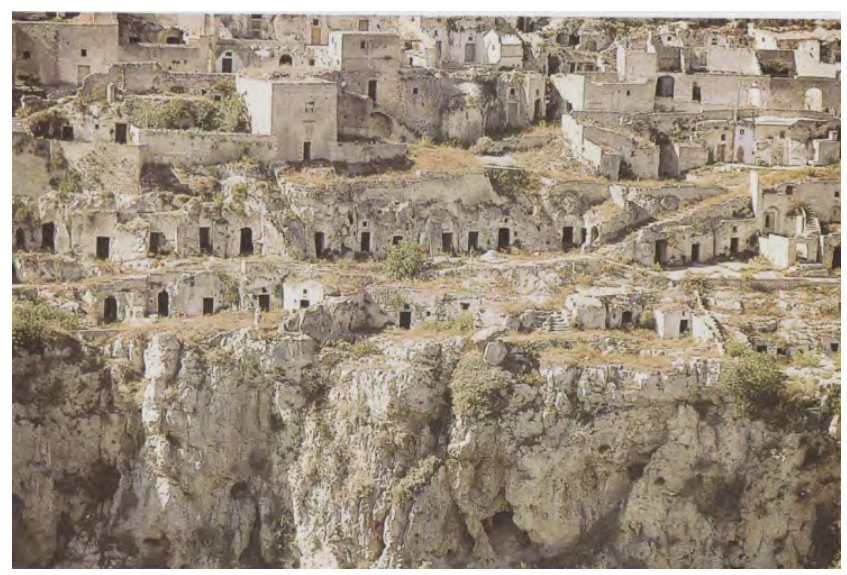

Figure 10. The cliff with straight steps of Sasso Caveoso. Source: Laureano, 1993 [2].

Another Sasso is called Barisano. Like for the Caveoso, this name could depend on its geographical orientation, in this case it points towards the North-West, to the city of Bari. Another interpretation connects it, instead, to the presence, during Roman times, of a house inhabited by the Barisius noble family, a surname later transformed into Barisano. The most origin of this name lies, however, in the root of the name, which is the same as baratro, mieaning "abyss". This Sasso is a settlement developed within an abyss; rocks are carved into slopes. Compared to the Caveoso it looks like it was built more intensively: in reality only the facades of buildings are constructed (Figure 11).

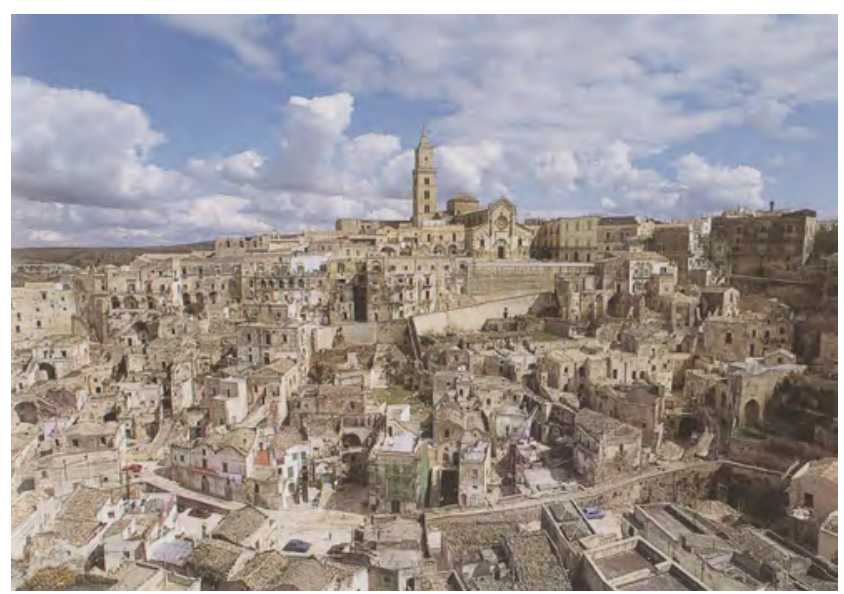

Figure 11. View of the Sasso Barisano. Source: Laureano, 1993 [2]

Many of the cavities bear the typical bell shape, initially employed for the collection of water to cope with the aridity typical of this area, later reused and transformed into housings. An example of reuse is testified by the entrance porch to the two aisles of the rock monastery of St. Nicholas of the Greeks, made from a large cistern bell.

The phenomenon of reuse, namely the ability to reinvent things and to find for them a new function, a phenomenon that is certainly not recent, implemented over time a perfect combination between water systems and cavities, and between the tank architecture and homes. Such a way of thinking about reuse contributed greatly to transform the architectural evolution of the Sassi, an architecture that does not destroy, but it includes.

It is enough to look at a typical fireplace that suddenly comes out at street level, or to explore the upper floors of a house and discover a food store that plunges deep into the bedrock, to sense, beneath the surface, the presence of an archaic reality: a reality completely embedded in the urban fabric, visible, for example, in the Idris complex emerging with its ancient rocks to dominate the Caveoso.

The brilliant ability of people to manage water, soil and energy in a sustainable way are peculiarities belonging to the population Matera that have never gone lost through time.

\section{Matera, Capital of Sustainability}

The candidacy of Matera as World Heritage Site has a meaning of great importance. It is the reversal of the usual system of evaluation of art centres and the emergence of new cultural values; it represents, a precious reference to all other the countries of the southern hemisphere. It expresses a conception of artistic heritage in which the presence of single great monuments is less critical than the overall urban texture and environmental space. Efforts and genius were expressed to use resources sparingly and efficiently. A continuum between landscape, architecture and human relations exists and it represents a true gift created at the time of the ancient historical settlements. The overall integration of the natural framework, the immense work of excavation and the constructions facing the Sassi, make of Matera an outstanding example of symbiosis between the site and the intervention of man. The Sassi of Matera, do not have the grandeur of Petra, the fabulous city of the Nabataeans in Jordan, with whom they share the name due to the common rocky nature; they do not possess the monumental architecture excavated at Lalibela in Ethiopia. They are, however, at difference of these, an example of the prolonged ability to create architectures and cities with few resources and through their appropriate use.

The pastoral economy of transhumance and the agricultural use of the Sassi valley as a system of climate protection provided shelter to men and to animals. They served as sites of storage, agro-pastoral production and water collection. The water flows coming from the higher plateau and the clay hills are trapped, channelled and distributed to the caves and to the eroding terraces. These 
are organized in a system of terraces that breaks the impetus of the water and promotes the formation of fertile soil. This structure is the plot matrix of an urban complex consisting of the composition of basic elements: caves, tuff buildings, roof gardens, canals and reservoirs, trails and their neighborhoods. It creates a global economy resulting from the proper management of scarce resources, an organization based on urban spaces and architecture of water, light and wind.

Due to all this, Matera offers an important example of sustainability, which is the ability to meet the needs of the present without compromising the ability of future generations to meet their own needs $[16,17]$. To achieve this, values like heritage, frugality, courage, passion, care and rural values become a model that may be exported to Europe thanks to the visibility that Matera get as European Capital of Culture.

The recent vision permeated the Sassi of new meaning; thirty years after complete depopulation occurred in the sixties, it promoted the return of the inhabitants in the nineties. Apology of the conflict between tradition and modernity, example of sustainable city, Matera is a metaphor for a new model and a proposal for the entire planet.

\section{The Underground Architecture of Matera: An Example of Resilience}

The scarcity of resources, the need to make proper and common use, the economy of land and water, the control of the energies of the sun and wind, the knowledge of the laws of fluid mechanics, guided the resilient organization of the Sassi of Matera. The action of man did not just follow the environment, but it turned it into a stratification of interventions based on the harmonious management of space. The terraces and the shelters of the transhumant pastoralism, the archaic methods to seek protection against heat and cold, the preservation of farming produce, the collection of water and their channelling into gardens, towards the clearing in front of the cave up to the tank, representing the hub through which neighbourhoods would find their organization, ... all these are components of the resilient matrix that is still identifiable today and which still supports the growth of the urban fabric.

To get an idea of the extraordinary ability of the people of Matera in implementing resilient forms of behaviour appropriate to the difficulties of the urban areas, it is necessary to refer to the implementation of water collection works, visible in the subsoil of Vittorio Veneto Sq., where the large tank, installed at the origin of the grabiglione Sasso Barisano, was made available. It has been functioning until the nineteenth century; a piece of work, which is part of the system of Matera underground structures representing an example of effective planning and management that throughout the centuries enhanced the resilience of the surrounding landscape [18, 19] (Figure 12).

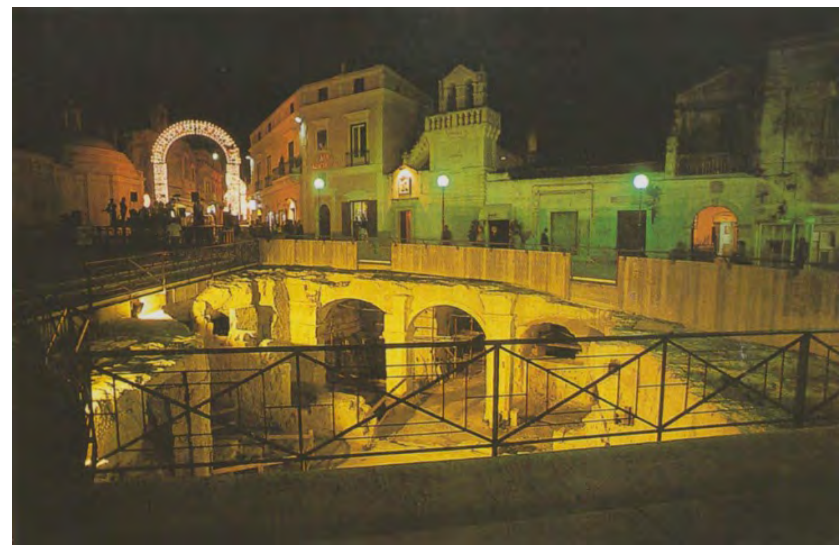

Figure 12. The neighborhood of Vittorio Veneto square. Source: Laureano, 1993 [2]

Resilience builds an interaction between individuals, society and the environment, and thus in different cultures and local contexts it acquires different expressions [9]. In the case of the Matera, the use of the underground part of the city, is explained by the fact that being an arid land, the knowledge of typical environmental hazards, the type of risk, in this case represented by drought, allowed the inhabitants to activate a protection strategy to defending the city. They distributed water masses intercepting them and collecting them right at the edge of steep sides of the canyon, using water tanks. These tanks collect rainwater, filter it and direct it in a controlled manner to the Sassi, thanks to the vertical disposition of the city, which allows the use of a network activated by gravity flow. This is an ingenious and harmonious housing system; it remained intact until the eighteenth century, as is made clear in the fresco of the city built in 1750 situated on the vault of the Archbishop's Palace. In the painting, you can follow the system of roads and the organization of the Sassi second drainage lines to the current Vittorio Veneto square (Figure 13).

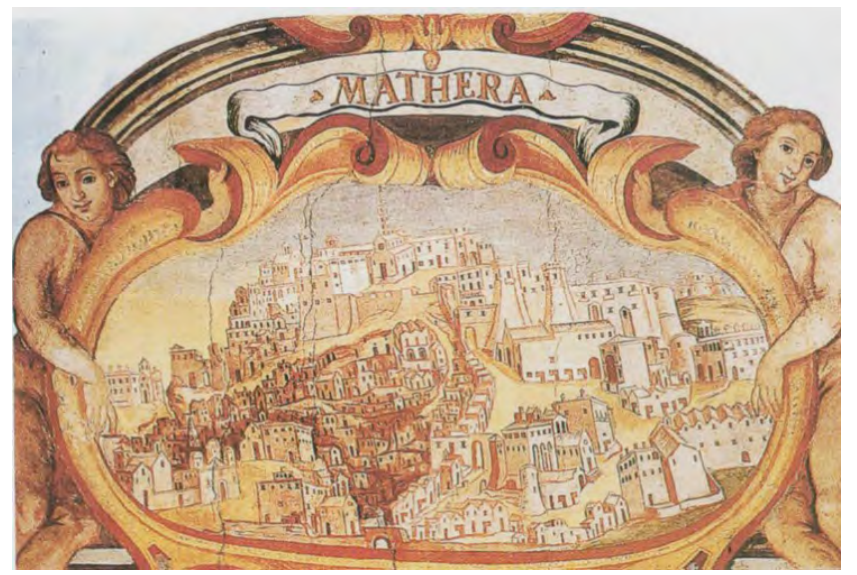

Figure 13. Fresco of the Archbishop's Palace showing Matera in 1750. Source: Laureano, 1993 [2]

By adding to this faithful representation of the urban system, the missing part of the riverbed of the Caveoso, protected by the Idris outcrop, the plateau cave system in 
front of Murgia, the pits and tanks that surround the Sassi from the flats, and marking all lines of flow of water, one can admire a full view of the complex ecosystem of the Sassi of Matera.

Resilience should not be considered as an element that is either there or not, but as the result of a process. It is the effect of an interaction over time between man and his environment, without actually creating anything new but enhancing knowledge itself. It implies knowing how one should be (risk awareness) and how one should act (the ability to implement behavior appropriate to different circumstances). It aims at improving not only the relationship between man and nature, but the way of representing this relationship; to rebuild "the relationship of territoriality, by which society, transforming Earth, transforms itself" [20]. The geomorphological framework is the background of the great resilience of Matera, prolonged through time in the design and in the construction of the built-up environment.

The experience of Matera can be generalized to countries of the southern Mediterranean and contributes to the definition of concrete examples of sustainable cities where the Sassi are an example and a laboratory, cited as an international success. The careful restoration created new professions, rehabilitated ancient crafts and marginalized identities, promoting economic prosperity and human progress. The preservation of physical signs became protection of intangible goods, a recovery of identity and of cultural and spiritual values. The Sassi, where, until the mid-nineties, not only the caves themselves, but also important buildings were sold at low prices, are in high demand today. More and more people settle there and they continuously rise in value. Matera went within a few years from a near complete lack of hotels to a great variety of structures, some of which built in underground caves and representing spectacular destination for a growing tourism. The recovery is not only the will of intellectuals but also a process driven from below, from the citizens themselves, supported by private investment and high economic returns.

Matera is a resilient city: able to recover from the terrible shock of the mid-twentieth century that led the city to be defined as a "national shame", today it has become one of the assets most renowned in the world, a model of sustainability and resilience for Europe and for the whole world.

\section{Conclusions}

It seems interesting to return briefly to the question raised in the introduction that is the game of reversal that characterized the case of Matera: a unique case in the world. After the evacuation of the early fifties, the Sassi were abandoned, forgotten for over thirty years as if suddenly centuries of history, life, traditions could be entirely erased. The very description given by Carlo Levi in Christ Stopped at Eboli or the appeal by Pier Paolo Pasolini, who shot in Matera the Gospel according to Matthew, reflected the state of deterioration that affected the Sassi of Matera, that led it to become a symbol of "national shame", the emblem of a Italian South backlog in conflict with modernity.

With the gradual reuse of the buildings, the main causes of deterioration of the Sassi disappeared. In 1992, the Sassi of Matera and the archaeological park and the natural rock civilization of Gravina were proposed for nomination to the World Heritage List. In 1993, Matera was declared World Heritage Site by UNESCO, recognizing in the Sassi the exceptional testimony of vanished civilizations, of architecture and a landscape that witnessed significant moments in the history of humankind, a major example of traditional human settlements, representing a culture that has, since its inception, maintained a harmonious relationship with its natural environment. Finally Matera was recognized as a site of timeless beauty, a marvel that now finds its ancient and infinite splendour, thanks to the awareness of its people, of its age-old traditions based on the ability to inhabit inhospitable places by creating the right relationship with the landscape. A site where managing scarce resources and the environment served to develop techniques to exploit primary assets for life, such as water, spreading it to all levels of the population.

Almost twenty years later, the inhabitants of Matera have proposed to the community a new challenge: Matera the European Capital of Culture, in an attempt to share with Europe and the World the story of its relationship with a winning environment.

The goal is to shift to a new culture of planning and cultural investment that would be based on key principles described in the course of this work: reuse, sustainable development, with particular attention to the resilience of the landscape.

Matera 2019 must be an opportunity to rediscover the beauty of the spaces we inhabit daily and above all it must represent not only an opportunity to wonder about the relationship between man and the environment, but also a different way of representing this relationship, by re-evaluating traditional values.

The restoration and the proper management of the Sassi are a model of extraordinary interest for all countries in Europe, in the whole Mediterranean and in the South, that have architectural realities and similar environmental quality often spread on a regional scale. An experience that remains settled on the materials and on the articles of our daily life and activities, made of brittle elements and susceptible to the attack of ongoing transformations. The case of Matera opens an innovative field of reflection and intervention. Therefore, it is necessary to look at it avoiding the influence of postmodernism; this could be a key to realize this fragile but harmonious relationship between man, the city and the landscape. During the postmodern era, the separation between the body and the environment is the symbol of the inability of our minds to draw a map of the great global, multinational and decentralized communicational network, in which we find ourselves caught as individual subjects [21]. Never before, however, 
Europe needs a narrative on the ability to reinvent, re-evaluate and renew itself, by rediscovering its lost bond with the environment. The Sassi of Matera is, therefore, the revelation of a new harmonious relationship between man and the natural environment.

\section{REFERENCES}

[1] C. Levi, Cristo si è fermato a Eboli, Einaudi, Torino, 1945.

[2] P. Laureano, Giardini di pietra. I Sassi di Matera e la civiltà mediterranea, Bollati Boringhieri, Torino, 1993.

[3] R. Giura Longo, Le origini e il popolamento dei Sassi di Matera, Montemurro, Matera, 1966.

[4] R. Giura Longo, Sassi e Secoli, Galleria Studio, Matera, 1966.

[5] R. Giura Longo, Breve storia della città di Matera, BMG, Matera, 1981.

[6] P. Laureano, Giardini di pietra: i Sassi di Matera, I. Pizzetti, F. Alberti (Eds.), Architetture nel paesaggio, Alinea, Firenze, 2000, pp. 25-30.

[7] T. Stigliani, Del Mondo Nuovo del Cavalier Tomaso Stigliani. Venti primi canti coi sommarii dell'istesso autore, dietro a ciaschedun d'essi, e con una lettera del medesimo in fine, la quale discorre sopra d'alcuni ricevuti avvertimenti intorno a tutta l’opera, in Piacenza, per Alessandro Bazacchi, 1617.

[8] T. Stigliani, Il Mondo Nuovo Poema eroico del Cav. Fr. Tomaso Stigliani diviso in trentaquattro canti cogli argomenti dell'istesso autore, in Roma, appresso Giacomo Mascardi, 1628.

[9] N. Tecco, Educazione geografica, resilienza e catastrofi naturali, C. Giorda, M. Puttilli (Eds.), Educare al territorio, educare il territorio. Geografia per la formazione, Carocci, Roma, 2011, 308-320.

[10] A.S. Masten, N. Garmezy, Risk, vulnerability, and protective factors in developmental psychopathology, B. Lahey, A. Kazdin, Advances in Clinical Child Psychology, vol. 8, Plenum, New York, 1985, 1-52.

[11] A.S. Masten, Resilience in developing systems: Progress and promise as the fourth wave rises, Development and Psychopathology, 19, 2007, 921-930.

[12] E.E. Werner, R.S. Smith, Vulnerable but Invincible: A Study of Resilient Children, McGraw-Hill, New York, 1982.

[13] S.S. Luthar, Resilience and Vulnerability: Adaptation in the Context of Childhood Adversities, Cambridge University Press, Cambridge, 2003.

[14] C. Inguglia, A. Lo Coco, Resilienza e vulnerabilità psicologica nel corso dello sviluppo, Il Mulino, Bologna, 2013.

[15] D. Ridola, Le grandi trincee preistoriche di Matera. La ceramica e la civiltà di quel tempo, Bollettino di Paletnologia italiana, Roma, 1924-1926, 44-46, pp. 3-83.

[16] G.H. Brundtland, Il futuro di noi tutti, Commissione mondiale per l'ambiente e lo sviluppo, Bompiani, Milano, 1990.

[17] A. Lanza, Lo sviluppo sostenibile, Il Mulino, Bologna, 1997.

[18] F. De Pascale, M. Bernardo, F. Muto, Hazardscape, territorial and individual resilience in an interdisciplinary study: the case of Pollino, Calabria, Southern Italy, G. Lollino et al. (Eds.), Engineering Geology for Society and Territory, Vol. 7, Education, Professional Ethics and Public Recognition of Engineering Geology, Springer International Publishing Switzerland, 2014, 109-113.

[19] F. De Pascale, M. Bernardo, F. Muto, S. D’Amico, R. Zumbo, P. Galea, M. Agius, Neogeography and seismic risk perception. A comparison between two case-studies: Calabria (Southern Italy), Malta, European Journal of Geography, 6, 1:64-83, March 2015, 64-83.

[20] G. Dematteis, La metafora geografica è postmoderna?, Bollettino della Società Geografica Italiana, 12, 8, 2003, 947-954.

[21] F. Jameson, Postmodernism, or the Cultural Logic of Late Capitalism, New Left Review, 146, 1984, 59-92. 